\title{
MaAreB, a GATA Transcription Factor, Is Involved in Nitrogen Source Utilization, Stress Tolerances and Virulence in Metarhizium acridum
}

\author{
Chaochuang Li ${ }^{1,2,3}$, Qipei Zhang ${ }^{1,2,3}$, Yuxian Xia ${ }^{1,2,3, *}$ and Kai Jin ${ }^{1,2,3, *(D)}$ \\ 1 Genetic Engineering Research Center, School of Life Sciences, Chongqing University, \\ Chongqing 401331, China; leezc90@163.com (C.L.); zhangqipei12201@yeah.net (Q.Z.) \\ 2 Chongqing Engineering Research Center for Fungal Insecticide, Chongqing 401331, China \\ 3 Key Laboratory of Gene Function and Regulation Technologies Under Chongqing Municipal Education \\ Commission, Chongqing 401331, China \\ * Correspondence: yuxianxia@cqu.edu.cn (Y.X.); jinkai@cqu.edu.cn (K.J.); Tel.: +86-23-65120990 (Y.X.)
}

check for updates

Citation: Li, C.; Zhang, Q.; Xia, Y.; Jin, K. MaAreB, a GATA Transcription Factor, Is Involved in Nitrogen Source Utilization, Stress Tolerances and Virulence in Metarhizium acridum. J. Fungi 2021, 7, 512. https://doi.org/ 10.3390/jof7070512

Academic Editor: Julianne Djordjevic

Received: 13 May 2021

Accepted: 24 June 2021

Published: 27 June 2021

Publisher's Note: MDPI stays neutral with regard to jurisdictional claims in published maps and institutional affiliations.

Copyright: (c) 2021 by the authors. Licensee MDPI, Basel, Switzerland. This article is an open access article distributed under the terms and conditions of the Creative Commons Attribution (CC BY) license (https:/ / creativecommons.org/licenses/by/ $4.0 /)$.

\begin{abstract}
The nitrogen catabolite repression (NCR) pathway is involved in nitrogen utilization, in which the global GATA transcription factor AreA plays an indispensable role and has been reported in many fungi. However, relatively few studies are focused on AreB, another GATA transcription factor in the NCR pathway and the functions of AreB are largely unknown in entomopathogenic fungi. Here, we characterized MaAreB in the model entomopathogenic fungus Metarhizium acridum. Sequence arrangement found that MaAreB had a conserved GATA zinc finger DNA binding domain and a leucine zipper domain. Disruption of $M a A r e B$ affected the nitrogen utilization and led to decelerated conidial germination and hyphal growth, decreased conidial yield, and lower tolerances to UV-B irradiation and heat-shock. Furthermore, the MaAreB mutant ( $\triangle M a A r e B$ ) exhibited increased sensitivity to CFW (Calcofluor white), decreased cell wall contents (chitin and $\beta-1,3$-glucan) and reduced expression levels of some genes related to cell wall integrity, indicating that disruption of $M a A r e B$ affected the cell wall integrity. Bioassays showed that the virulence of the $\triangle M a A r e B$ strain was decreased in topical inoculation but not in intra-hemocoel injection. Consistently, deletion of MaAreB severely impaired the appressorium formation and reduced the turgor pressure of appressorium. These results revealed that $M a A r e B$ regulated fungal nitrogen utilization, cell wall integrity and biological control potential, which would contribute to the functional characterization of AreB homologous proteins in other insect fungal pathogens, and even filamentous fungi.
\end{abstract}

Keywords: Metarhizium acridum; GATA transcription factor; MaAreB; nitrogen utilization; stress response; virulence

\section{Introduction}

There are many fungi in the natural environment; some are pathogenic and are a threat to human health, agriculture and forestry, such as Aspergillus fumigatus, Candida albicans, A. flavus, Fusarium graminearum, and Magnaporthe oryzae [1,2]. Some are important biological control fungi, which can be used to control crop diseases and pests, such as Trichoderma harzianum, Beauveria bassiana and Metarhizium anisopliae [3-5]. Entomopathogenic fungi, as an important class of insecticidal microbes, are important regulators of the insect population in nature, and have been applied to the control of agricultural and forestry pests $[6,7]$. Similar to many plant fungal pathogens, the conidia of insect fungal pathogens, like $B$. bassiana, could adhere to the host cuticles and penetrate these via the infection structure appressorium under the combination of turgor pressure and cuticle-degrading enzymes [8-10]. Under natural conditions, fungi have to cope with a variety of environmental challenges, such as temperature, ultraviolet rays, nutritional restriction conditions, etc. [11].

Nitrogen is a necessary influencing factor for fungal survival. Fungi can uptake some kinds of compound as nitrogen sources, but other nitrogen sources will not be assimilated 
in the presence of preferentially used ammonium or glutamine; if not, they can assimilate other nitrogen sources, such as nitrate and urea $[12,13]$. This phenomenon of nitrogen utilization is well known as nitrogen metabolite repression (NMR), also called nitrogen catabolite repression (NCR) in Saccharomyces cerevisiae, which mainly regulates genes related to nitrogen utilization at the transcription level [12]. In ascomycetes, NCR is mediated by GATA transcription factors, and four GATA transcription factors are characterized in S. cerevisiae, namely Gln3 and Gat1, which play positive regulatory roles, and Dal80 and Gzf3, which play negative regulatory roles [11]. However, only two GATA transcription factors, AreA and AreB, in the NCR pathway were found in filamentous fungi [14]. The AreA homologous proteins have been characterized in many fungi, such as AreA in A. nidulans [15], Nit2 in N. crassa [16] and Nut1 in M. oryzae [17]. AreA can activate the expression of genes that make full use of non-preferential nitrogen sources to relieve nitrogen repression in the absence of preferential nitrogen sources [18]. Accumulated research has indicated that AreA plays important roles in nitrogen utilization and the growth and development of fungi [19-22].

AreB is another GATA transcription factor, involved in regulating nitrogen metabolism in A. nidulans [23]. AreB is homologous to Dal80 and Gzf3, and may play a negative regulatory role by competing with the promoter binding sites with AreA [14,23]. The overexpression of $a r e B$ can repress the transcription of genes regulated by AreA in A. nidulans [14], and the overexpression of $n r e B$, a homologous gene of $A r e B$, would down-regulate the expression of nitrate assimilation related genes in P. chrysogenum [24], indicating that AreB acts as a repressor and negatively regulates the activity of AreA. Furthermore, mepC [25] and $n m r 1$ [26], the AreA-dependent genes, are highly expressed in $\triangle A r e B$ mutant, indicating that AreA and AreB share the same target genes, but with different regulation pathways [18]. Interestingly, asd4, a homologous gene of $A r e B$, does not regulate nitrogen metabolism, but regulates the development of ascospores in N. crassa [27]. In F. fujikuroi, AreB can simultaneously play positive and negative regulatory roles in nitrogen metabolism, and both AreA and AreB play important roles in the biosynthesis of gibberellin [11]. In $M$. oryzae, asd 4 is required for nitrogen metabolism including glutaminolysis and loss of asd4 would result in failure of appressorium formation and abolishment of virulence [28]. To date, however, little is known about the involvement of the AreB homologous protein in potential biological control of entomopathogenic fungi.

In this study, MaAreB, a GATA transcription factor AreB homologous protein, was identified in $M$. acridum. To reveal the underlying roles of $M a A r e B$, we characterized $M a A r e B$ by gene knockout and complementation technology in M. acridum. This showed that $M a A r e B$ not only played important roles in regulating nitrogen utilization, but also in the growth characteristic, stress tolerance, cell wall integrity and virulence of $M$. acridum. These results suggest a multifunctional role of $M a A r e B$ in development and biological control potential for M. acridum.

\section{Materials and Methods}

\subsection{Strains and Culture Conditions}

The M. acridum wild-type strain CQMa102 (WT), MaAreB-disruption strain ( $\triangle$ MaAreB) and complemented strain (CP) were cultured on $1 / 4$ SDAY $(0.5 \%$ yeast extract, $1 \%$ glucose, $0.25 \%$ peptone and $1.8 \%$ agar, $w / v)$, Czapek-dox (CZA) $\left(0.001 \% \mathrm{FeSO}_{4}, 0.1 \% \mathrm{~K}_{2} \mathrm{HPO}_{4}\right.$, $0.05 \% \mathrm{KCl}, 0.2 \% \mathrm{NaNO}_{3}, 0.05 \% \mathrm{MgSO}_{4}, 3 \%$ sucrose and $1.8 \%$ agar, $\left.w / v\right)$, and/or modified CZA medium at $28^{\circ} \mathrm{C}$ for hours or days. E. coli BGT1 (Solarbio, Beijing, China) was used to construct the recombinant plasmids, and Agrobacterium tumefaciens AGL1 (Solarbio, Beijing, China) was used for the genetic transformation of $M$. acridum.

\subsection{Bioinformatics Analysis}

The protein sequences of MaAreB (NCBI reference sequence, MAC_07065) and its homologous proteins were retrieved and downloaded from GenBank (https:/ / www.ncbi. nlm.nih.gov/protein/) (accessed on 3 March 2021). Domains in MaAreB protein were 
predicted online via SMART interface (http:/ / smart.emblheidelberg.de/) (accessed on 3 March 2021). Multiple sequence alignments were performed by the DNAMAN program, and the neighbor-joining tree was constructed by MEGA6 under the condition of default settings and 1000 bootstrap replicates [29].

\subsection{Construction of the Mutants}

To construct the MaAreB-disruption vectors, about 1000-bp up- and down-stream fragments of $M a A r e B$ were cloned from WT genomic DNA and inserted into pK2-SM-F and pK2-SM-R vectors [30] to form the gene knockout vectors, pK2-SM-MaAreB-F and pK2SM-MaAreB-R (Figure S1A). The DNA and promoter sequence of MaAreB was amplified and inserted into $\mathrm{pK} 2$-sur vector [31] to form the complementation plasmid, pK2-surMaAreB (Figure S1B). Both knockout and complementation recombinant vectors were transferred into AGL1 for fungal transformation [32]. The $\triangle M a A r e B$ and CP transformants were screened on CZA plates supplemented with $0.5 \mathrm{~g} / \mathrm{L}$ glufosinate-ammonium (Sigma, St. Louis, MO, USA) or 0.02 g/L chlorimuron ethyl (Sigma, Bellefonte, PA, USA), respectively. Firstly, the fragments of target gene and resistance genes were amplified for preliminary verification of the transformants. On the other hand, Southern blotting was used for further verification via DIG High Prime DNA Labeling and Detection Starter Kit I (Roche, Basel, Switzerland) (Figure S1C). All primers are listed in Table S1.

\subsection{Growth Characteristic Assays}

The conidia of WT, $\triangle M a A r e B$ and CP strains, cultured on 1/4SDAY for 15 days, were used for preparation of conidial suspensions $\left(10^{6}\right.$ or $10^{7}$ conidia $\left./ \mathrm{mL}\right)$. For examination of the conidial germination rate and observation of hyphal morphological development, $100 \mu \mathrm{L}$ conidial suspensions $\left(10^{7}\right.$ conidia $\left./ \mathrm{mL}\right)$ were pipetted and evenly coated on $1 / 4$ SDAY plate, followed by incubating for hours, then the germination of conidia was counted every two hours [33], and photographs taken every three hours, to record the mycelial growth, with a digital light microscope (MOTIC, Xiamen, China). For determination of the conidial yield, $2 \mu \mathrm{L}$ conidial suspensions $\left(10^{6}\right.$ conidia $\left./ \mathrm{mL}\right)$ were spotted onto $1 / 4 \mathrm{SDAY}$ or modified CZA medium and cultured at $28{ }^{\circ} \mathrm{C}$ for days, and every colony was broken in $1 \mathrm{~mL} 0.1 \%$ Tween- 80 to count the number of conidia with a hemocytometer on different days [33]. To analyze the nitrogen utilization, we improved the CZA medium and replaced nitrate with $10 \mathrm{mM}\left(\mathrm{NH}_{4}\right)_{2} \mathrm{SO}_{4}$, Glutamine, Glutamate or Proline to act as the sole nitrogen source, respectively. Two microliters of conidial suspensions $\left(10^{6}\right.$ conidia $\left./ \mathrm{mL}\right)$ were spotted onto modified CZA medium and cultured at $28^{\circ} \mathrm{C}$ for 7 days to observe the colony morphology and determine the conidial yield.

\subsection{Stress Tolerance Assays}

The tolerances of M. acridum to UV-B and heat-shock resistance were tested as described previously [34]. Briefly, in the UV-B tolerance test, $50 \mu \mathrm{L}$ conidial suspensions $\left(10^{7}\right.$ conidia $\left./ \mathrm{mL}\right)$ of different fungal strains were evenly spread on $1 / 4 \mathrm{SDAY}$ plates, followed by exposure to UV-B irradiation $\left(1350 \mathrm{MW} / \mathrm{m}^{2}\right)$ for $1.25 \mathrm{~h}, 2.50 \mathrm{~h}, 3.75 \mathrm{~h}$ and 5.00 $\mathrm{h}$, which provided total doses of $6.075,12.150,18.225,24.300 \mathrm{~kJ} / \mathrm{m}^{2}$, respectively. A $40-\mathrm{W}$ fluorescent lamp was used to provide the UV-B irradiation, and the solid plates were evenly distributed side by side on both sides under the lamp. For heat-shock tolerance test, the conidial suspensions $\left(10^{7}\right.$ conidia $\left./ \mathrm{mL}\right)$ of each strain were treatment in a $45^{\circ} \mathrm{C}$ water bath for hours, followed by spreading $50 \mu \mathrm{L}$ evenly on $1 / 4 \mathrm{SDAY}$ every three hours. All strains treated with UV-B irradiation and heat-shock were cultured for $20 \mathrm{~h}$ to examine the conidial germination.

To analyze cell wall integrity, $2 \mu \mathrm{L}$ conidial suspensions $\left(10^{6}\right.$ conidia $\left./ \mathrm{mL}\right)$ of each strain were spotted on 1/4SDAY (control) or supplemented with $150 \mu \mathrm{g} / \mathrm{mL}$ cell wall perturbing agent $\mathrm{CFW}$, then incubated for 7 days at $28^{\circ} \mathrm{C}$, followed by observation of the colony growth and calculation of the relative inhibition rates [35]. 


\subsection{Determination of Cell Wall Composition}

The cell wall contents, chitin, $\beta-1,3$-glucan and mannoproteins, of $M$. acridum were determined according to the previous study [36]. Briefly, hyphae of the WT, $\triangle M a A r e B$ and CP strains were respectively inoculated in a $40 \mathrm{~mL} 1 / 4 \mathrm{SDY}$ liquid medium $(1 / 4$ SDAY without agar) and cultured at $28{ }^{\circ} \mathrm{C}$ with $220 \mathrm{rpm}$ for 3 days. Then, the hyphae were harvested and washed with $2 \%$ SDS four times, followed by lyophilizing for $24 \mathrm{~h}$. Five milligrams (dry weight) hyphae were consumed for each determination. For determination of the chitin content, hydrochloric acid was used to hydrolyze fungal cell wall, and glucosamine was used as the standard. For determination of $\beta-1,3$-glucan content, sodium hydroxide was used to treat the fungal cell wall to obtain the alkali-insoluble fraction, followed by degrading with zymolyase 100-T, and laminaripentaose (Sigma, St. Louis, MO, USA) was used as the standard. To detect the content of mannoprotein, sodium hydroxide was used to extract the mannoprotein in each strain. The standard curve of bovine serum albumin was made via Folin-phenol reagent method.

\subsection{Quantitative Reverse Transcription PCR ( $q$ RT-PCR) Analysis}

The mature (15-day-old) conidia on 1/4SDAY medium were harvested and used to detect the expression of genes involved in the tolerances to UV-B, heat-shock, or the cell wall integrity. Appressoria of each strain were collected from the locust hind wings after $27 \mathrm{~h}$ of incubation at $28{ }^{\circ} \mathrm{C}$ to detect the expression of genes involved in fungal adhesion, cuticle penetration, or glycerol synthesis. The RNAs of fungal cells (conidia and appressoria) were extracted with fungal RNA Kit (CoWin Biosciences, Beijing, China). PrimeScript ${ }^{\mathrm{TM}}$ RT reagent Kit with gDNA Eraser (TaKaRa, Dalian, China) was used for synthesising cDNA. qRT-PCR was performed using SYBR ${ }^{\circledR}$ Premix Ex TaqTM (TaKaRa, Dalian, China). M. acridum gpdh (EFY84384) acted as the reference gene, and the data were analyzed according to the $2^{-\Delta \Delta \mathrm{Ct}}$ method [37]. Forty cycles were performed for all experiments. The details of CT value, amplicon length, and PCR efficiencies for each primer pair are provided in supplementary Table S2. The primers used for qRT-PCR are listed in supplementary Table S1.

\subsection{Insect Bioassays}

Topical inoculation and intra-hemocoel injection methods were used to investigate the virulence of the WT, $\triangle M a A r e B$ and $C P$ strains as described previously [38]. Briefly, 5 $\mu \mathrm{L} 10^{7}$ conidia/mL conidial suspensions were dropped on the pro-nota of a fifth-instar locust nymph as topical inoculation test, and liquid paraffin acted as control. Five microliters $10^{6}$ conidia $/ \mathrm{mL}$ of conidial suspensions were injected into the hemolymph of a fifth-instar locust nymph as intra-hemocoel injection test, and sterile water was used as the control. The bioassay environment was maintained in a stable photoperiod (16-h light and 8-h dark) with an ambient temperature of $28^{\circ} \mathrm{C}$. Three replicates of each treatment ( $n=30$ locusts) were performed, and the experiment was repeated three times. The mortality was recorded every half day until all the test insects had died. Virulence of each strain was estimated with the $\mathrm{LT}_{50}$ (the mean $50 \%$ lethality time). In order to observe the growth of M. acridum in locust hemolymph, $600 \mu \mathrm{L}$ blood for each treatment were collected to count the number of hyphal bodies and quantify the gDNA concentrations of the M. acridum, using quantitative PCR with the specificity ITS primers [39]. 


\subsection{Infection Structure Development Assays}

Conidial germinations and appressorium formations of the WT, $\triangle M a A r e B$ and $C P$ strains were determined as previously described [40]. Appressoria from different fungal strains were treated with different concentrations of PEG8000 to analyze the appressorial turgor pressure. The neutral lipids were stained with Nile Red as described previously [41], and the fluorescence intensity of the neutral lipids in appressorium was measured by ImageJ software.

\subsection{Statistical Analysis}

The data were presented as the mean \pm SD and analyzed using ANOVA (one-way analysis of variance) with the SPSS 24.0 program. The differences were analyzed with Tukey's HSD test. Three biological replicates were performed for each result.

\section{Results}

3.1. Bioinformatics Analysis and Generation of MaAreB Mutants

$M a A r e B$ was cloned from the genomic DNA of the WT strain; the DNA sequence was $1152 \mathrm{bp}$ with one intron. The ORF (open reading frame) was $1098 \mathrm{bp}$, encoding 365 amino acids. The physical and chemical properties of $\mathrm{MaAreB}$ were analyzed in silico, showing that the protein mass was $39.77 \mathrm{kDa}$, and the isoelectric point was 4.76. MaAreB encoded a GATA transcription factor with a zinc finger DNA binding domain at the $\mathrm{N}$-terminal and a leucine zipper domain at the C-terminal. Both domains were highly conserved in fungi, and the identity was $51.30 \%$ by protein sequence alignment of MaAreB with its homologs (Figure 1A). The homologous proteins of AreB, such as Asd4, Gzf3, or Dal80, were found in many fungi, and the phylogenetic tree analysis showed that MaAreB was relatively close to the homologous proteins of filamentous fungi in evolution, and far from yeast (Figure 1B).

According to the principle of homologous recombination, the $\triangle M a A r e B$ strain was obtained by replacing the $1.1 \mathrm{~kb} M a A r e B$ gene with the bar cassette (Figure S1A). The CP strain was constructed by the principle of random insertion (Figure S1B). All the fungal strains were verified by Southern blotting (Figure S1C). 

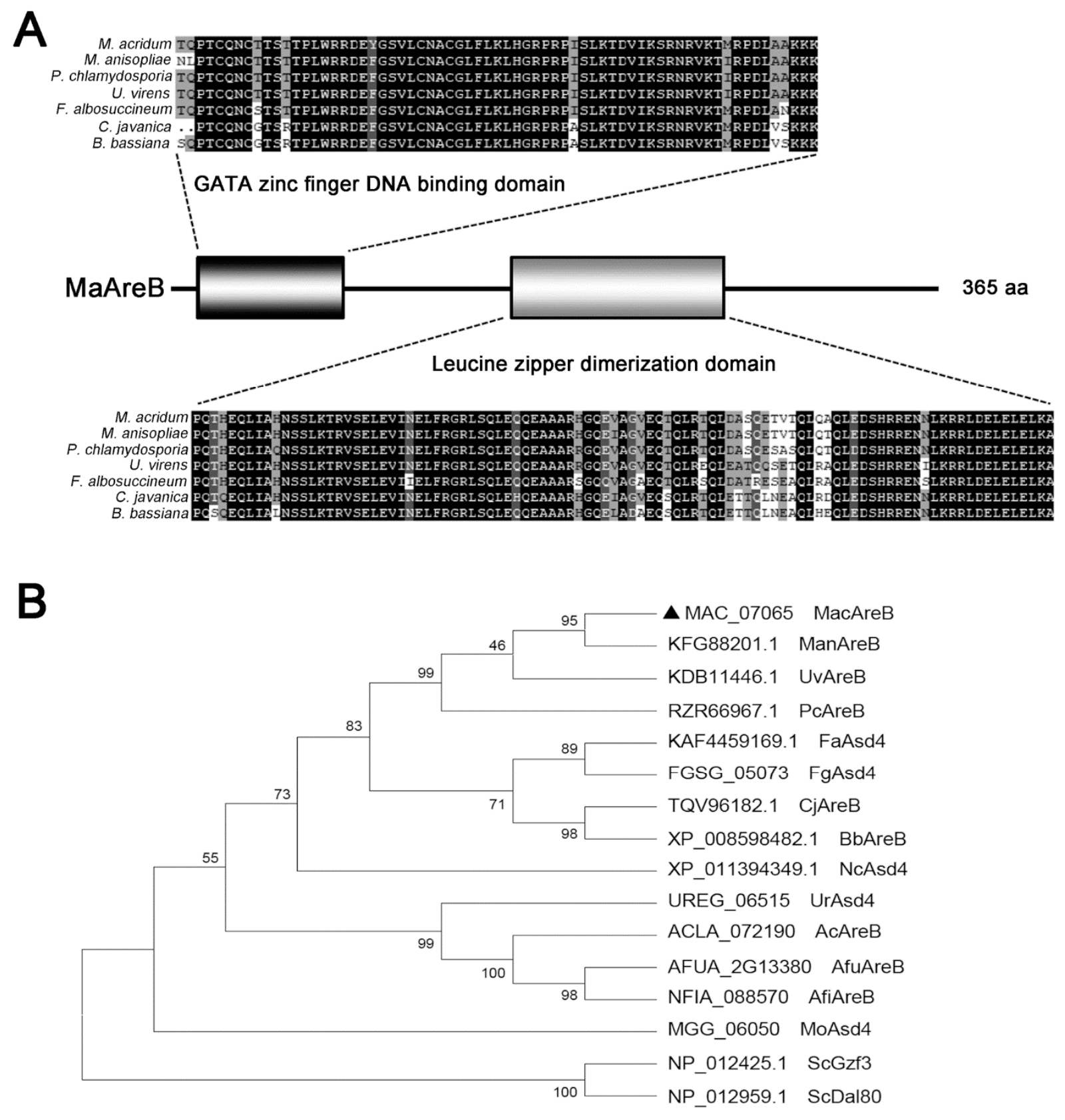

0.1

Figure 1. Sequence and phylogenetic analysis of MaAreB. (A) Conserved domain arrangements of the MaAreB and its orthologues in other fungal species. (B) Phylogenetic tree analysis of AreB proteins in multi-species. AreB, Asd4, Gzf3 and Dal80 are orthologues. Mac, Metarhizium acridum. Man, Metarhizium anisopliae. Uv, Ustilaginoidea virens. Pc, Pochonia chlamydosporia. Fa, Fusarium al-bosuccineum. Fg, Fusarium graminearum. Cj, Cordyceps javanica. Bb, Beauveria bassiana. Nc, Neurospora crassa. Ur, Uncinocarpus reesii. Ac, Aspergillus clavatus. Afu, Aspergillus fumigatus. Afi, Aspergillus fischeri. Mo, Magnaporthe oryzae. Sc, Saccharomyces cerevisiae. The triangle represented the AreB homologous protein in M. acridum.

\subsection{MaAreB Was Involved in the Regulation of Nitrogen Utilization}

AreB is a core member of NCR pathway and plays an important role in nitrogen utilization [14]. Thus, the WT, $\triangle M a A r e B$ and $C P$ strains were grown on modified CZA media, which were replaced the nitrate in CZA with $10 \mathrm{mM}\left(\mathrm{NH}_{4}\right)_{2} \mathrm{SO}_{4}$, glutamine, glutamate or proline, respectively. The results showed that the colonies of $\triangle M a A r e B$ grown on CZA media containing various nitrogen resources, except for ammonium, were smaller compared to the WT or CP strain (Figure $2 \mathrm{~A}, \mathrm{~B}$ ). The conidial yield of the $\triangle M a A r e B$ strain 
decreased slightly with no significant difference to the WT or CP strain grown on glutamate as the sole nitrogen source, but was significantly decreased when nitrate, glutamine or proline was used as the sole nitrogen source (Figure 2C). These data evidenced that MaAreB was involved in regulating nitrogen utilization.
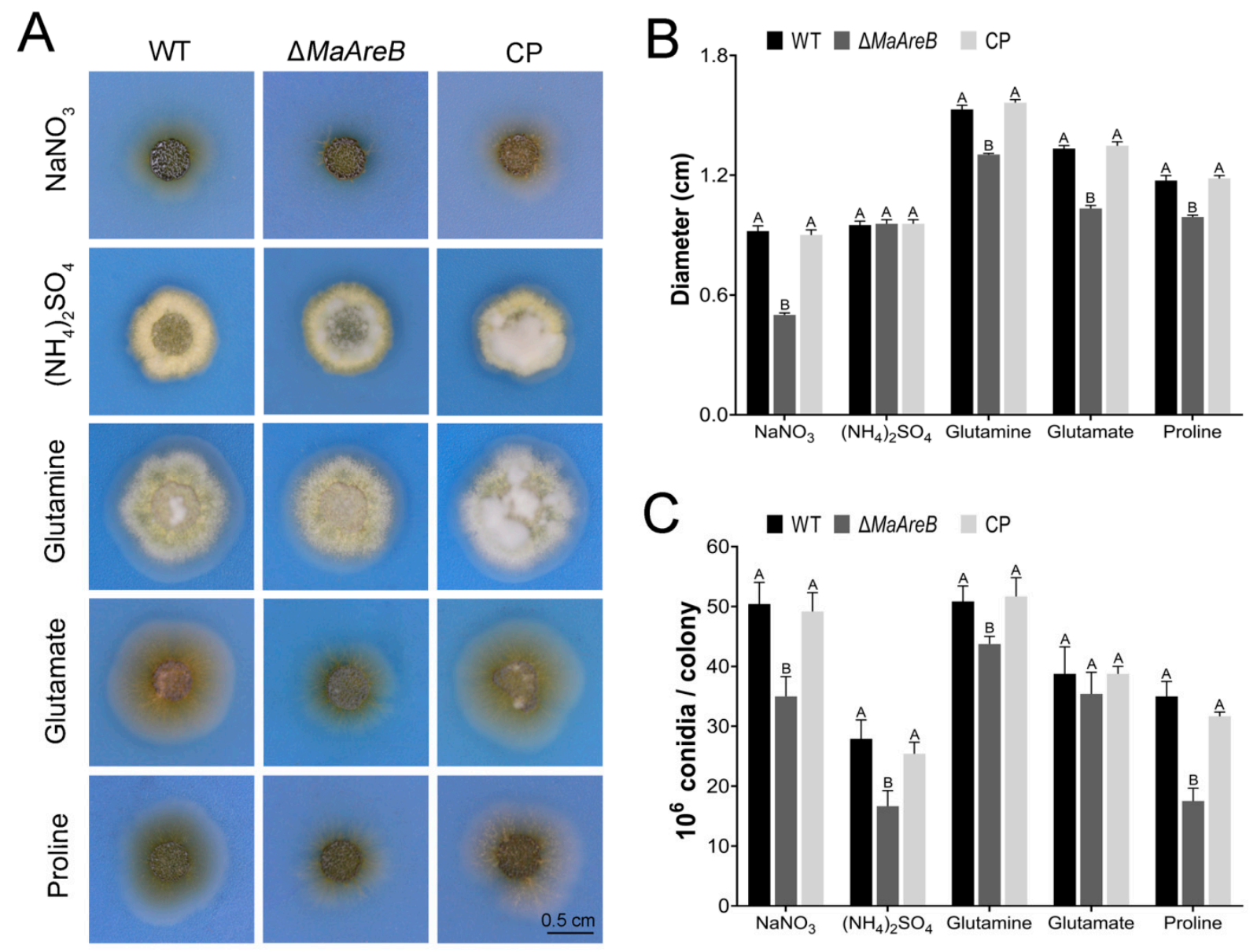

Figure 2. MaAreB was involved in regulating nitrogen utilization. Colony morphology (A), colony diameter (B) and conidial yield (C) of the WT, $\triangle M a A r e B$ and $\mathrm{CP}$ strains on modified $\mathrm{CZA}$ and cultured at $28{ }^{\circ} \mathrm{C}$ for 7 days. The concentrations of all nitrogen sources were $10 \mathrm{mM}$. A\&B, $p<0.05$ (Tukey's HSD). The $p$-values in Figure 2B,C were listed in supplementary Table S3.

\subsection{Deletion of MaAreB Affected Conidial Germination, Hyphal Growth and Conidiation}

To analyze the growth characteristics of the WT, $\triangle M a A r e B$ and $C P$ strains, we tested the conidial germinations, the macroscopic and microscopic growth morphologies, and the conidial yield of fungal strains grown on 1/4SDAY. The results showed that although there was no significant difference in colony morphology among the WT, $\triangle M a A r e B$ and $C P$ strains (Figure $3 \mathrm{~A}$ ), the germination rate of $\triangle M a A r e B$ strain was significantly slower at 2 , $4,6,8$ and $10 \mathrm{~h}$ (Figure $3 \mathrm{~B}$ ). The $\mathrm{GT}_{50}$ (the mean $50 \%$ germination time) of the $\triangle M a A r e B$ strain $(6.90 \pm 0.23 \mathrm{~h})$ was significantly prolonged compared with the WT $(5.25 \pm 0.20 \mathrm{~h})$ or $\mathrm{CP}(5.43 \pm 0.19 \mathrm{~h})$ strain (Figure $3 \mathrm{C})$. Microscopic observation showed that the WT and CP strains began to yield conidia at $18 \mathrm{~h}$, while the $\triangle M a A r e B$ strain did at $21 \mathrm{~h}$ (Figure 3D). Furthermore, the conidial yield of the $\triangle M a A r e B$ strain significantly reduced (Figure $3 E$ ). Taken together, it revealed that the $M a A r e B$ contributed to the conidial germination and the conidiation of M. acridum. 

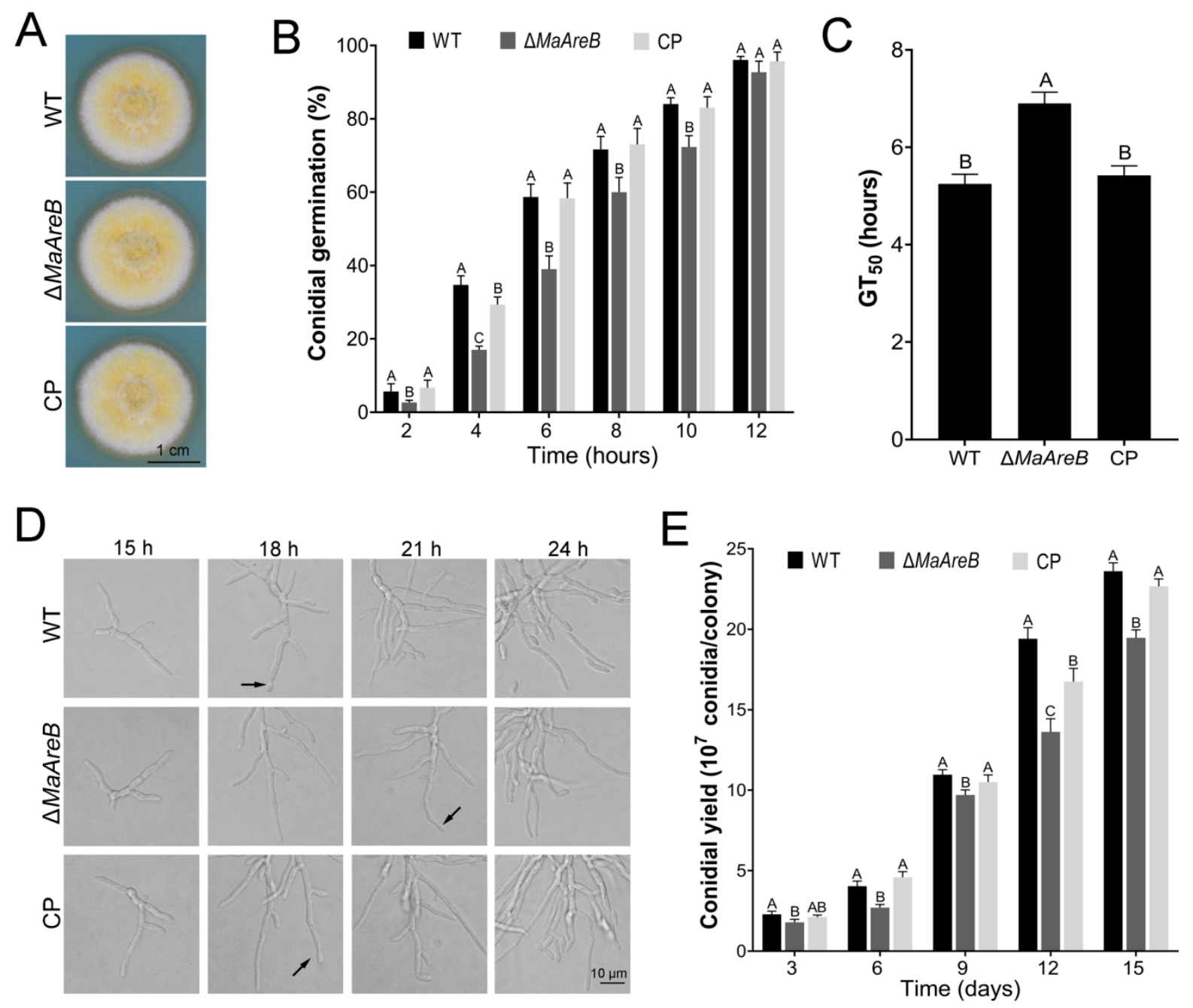

Figure 3. Deletion of $M a A r e B$ affected conidial germination, hyphal growth and conidiation. (A) Colonies of the WT, $\triangle M a A r e B$ and $C P$ strains cultured at $28^{\circ} \mathrm{C}$ for 7 days. (B) The germination rates of each strain at different time points. The $\mathrm{GT}_{50}(\mathrm{C})$, microscopic observation of conidiation (D) and conidial yield (E) of each strain. All fungal strains were grown on $1 / 4$ SDAY. The arrows in Figure 3D indicated the conidium formed at the tip of the hypha. $A \& B, A \& C$ and $B \& C, p<0.05$ (Tukey's HSD). The $p$-values in Figure 3B,C,E are listed in supplementary Table S3.

\subsection{Deletion of MaAreB Weakened the Stress Tolerances to UV-B Irradiation and Heat-Shock}

To clarify the effect of $M a A r e B$ on stress tolerances, the conidial germination rates of fungal strains were determined after treating with UV-B and heat-shock. These results showed that the conidial germination rate of $\triangle M a A r e B$ was sharply decreased under UV-B treatment at $2.50 \mathrm{~h}, 3.75 \mathrm{~h}$ and $5.00 \mathrm{~h}$ (Figure $4 \mathrm{~A}$ ). The $\mathrm{IT}_{50}$ (mean 50\% inhibition time) of the $\triangle M a A r e B$ strain $(3.65 \pm 0.04 \mathrm{~h}$ ) was markedly decreased compared with the WT $(4.51 \pm 0.16 \mathrm{~h})$ or CP $(4.34 \pm 0.12 \mathrm{~h})$ strain (Figure $4 \mathrm{~B})$. Furthermore, the transcription of the UV-B tolerance-related genes, MaUve1, MaWC1 and MaPhr, were significantly decreased in $\triangle M a A r e B$ (Figure $4 \mathrm{C}$ ). After being treated with heat-shock, the germination rate of the $\triangle M a A r e B$ strain also decreased significantly (Figure $4 \mathrm{D}$ ). The $\mathrm{IT}_{50}$ of $\triangle M a A r e B(9.62 \pm 0.41 \mathrm{~h})$ was significantly lower than that of the WT $(12.26 \pm 0.63 \mathrm{~h})$ or CP $(11.73 \pm 0.53 \mathrm{~h})$ strain (Figure 4E). In addition, the MaUbi1 gene related to the heat-shock protection of fungus was significantly down-regulated in $\triangle M a A r e B$ (Figure $4 \mathrm{~F}$ ). In summary, $M a A r e B$ played critical roles in fungal tolerances to UV-B irradiation and heat-shock. 

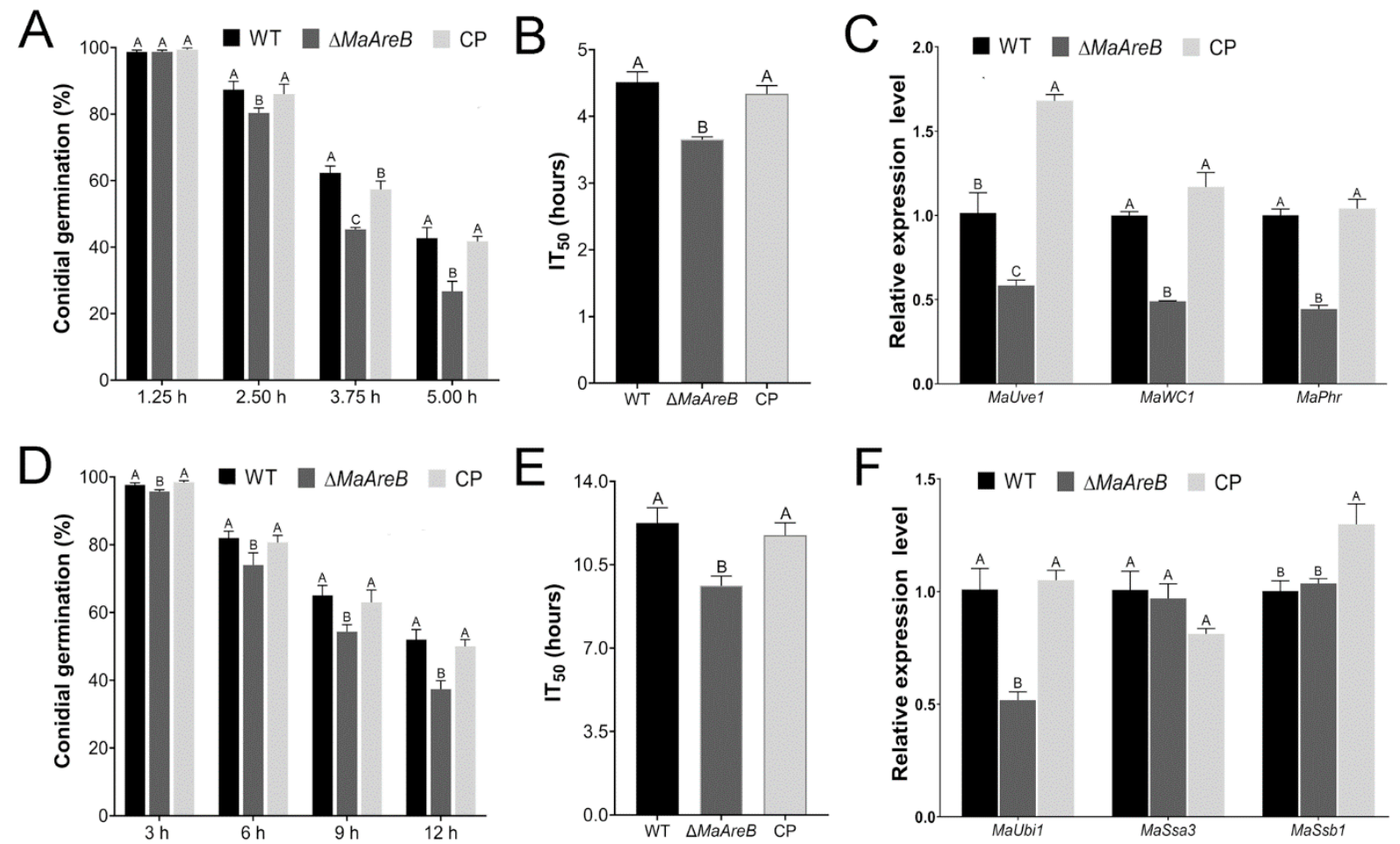

Figure 4. Deletion of $M a A r e B$ weakened tolerances to UV-B irradiation and heat-shock. Conidial germination of the WT, $\triangle M a A r e B$ and CP strains with UV-B irradiation (A) and heat-shock (D) treatments. The $\mathrm{IT}_{50}$ of each strain with UV-B irradiation (B) and heat-shock (E) treatments. Transcription level of genes involved in fungal tolerances to UV-B irradiation (C) and heat-shock (F). A\&B, A\&C or B\&C, $p<0.05$ (Tukey's HSD). The $p$-values in Figure 4A-F are listed in supplementary Table S3.

\subsection{Disruption of MaAreB Affected the Cell Wall Integrity}

The fungal cell wall plays crucial roles in fungal resistance to various adversities [42]. To further analyze the influence of $M a A r e B$ on the cell wall integrity of M. acridum, we added CFW into the 1/4SDAY to observe the growth of each strain. It was found that the colony of the $\triangle M a A r e B$ strain was smaller than those of the WT and CP strains (Figure $5 \mathrm{~A}$ ), and the relative inhibition rate of the $\triangle M a A r e B$ strain increased dramatically compared to the WT or CP strain (Figure 5B). Furthermore, the hyphal growth of the $\triangle M a A r e B$ strain was significantly inhibited by CFW (Figure 5CMaAreB affected the cell wall integrity. Thus, the cell wall components of each strain were measured. As a result, the contents of chitin and $\beta$-1,3-glucan decreased significantly when the $M a A r e B$ gene was deleted, but the content of mannoproteins was not affected (Figure 5D). Meanwhile, some genes related to cell wall integrity, such as chitin synthase genes MaChsI, MaChsII, MaChsIII, MaChsIV, MaChsV, MaChsVI, MaChsVII and $\beta$-1,3-glucan synthase gene MaFks1, were significantly down-regulated in the $\triangle M a A r e B$ strain (Figure 5E). Apparently, these results revealed that disruption of $M a A r e B$ affected the cell wall composition and structure of M. acridum. 

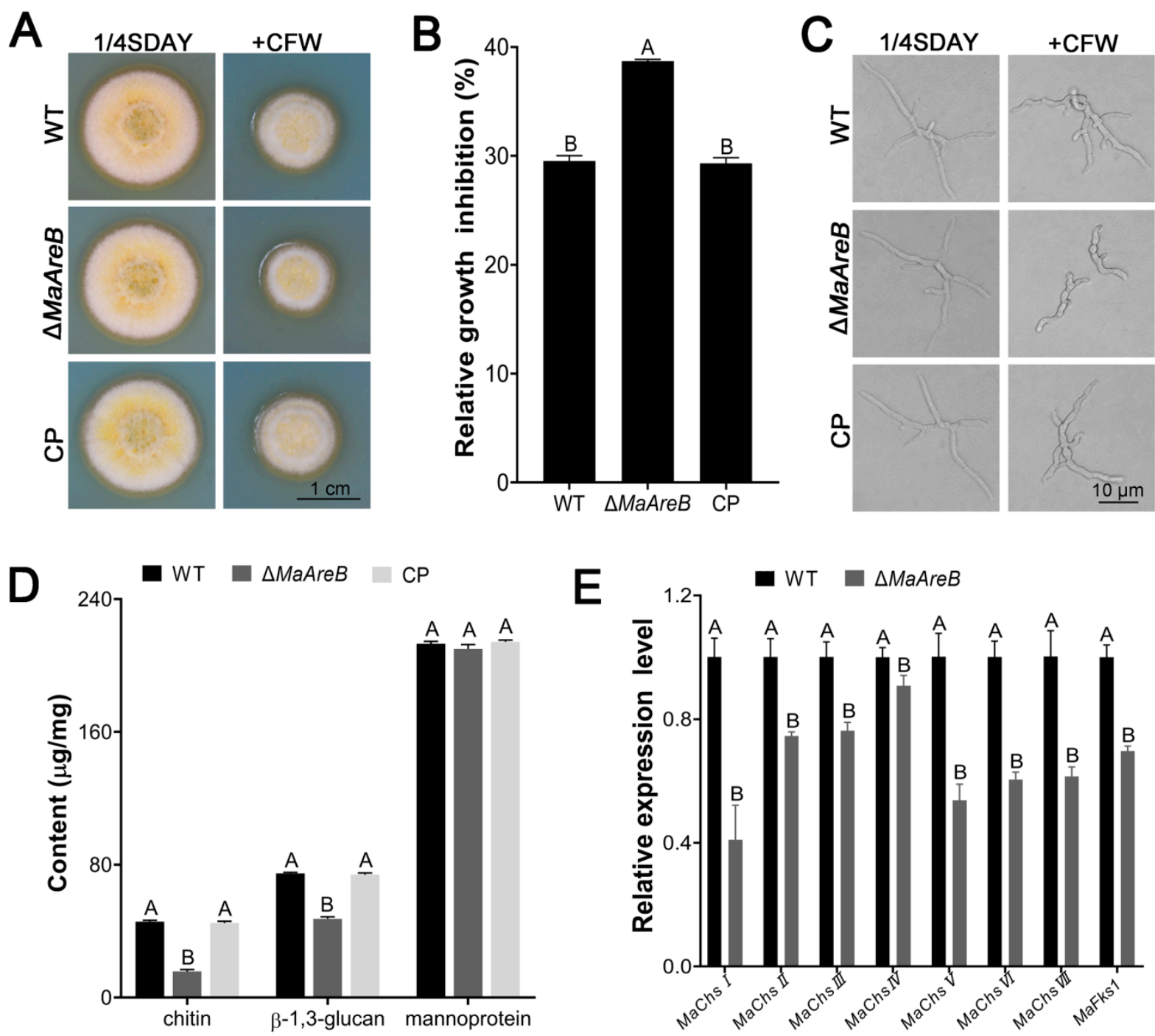

Figure 5. Disruption of MaAreB affected the cell wall integrity. (A) Growth of the WT, $\triangle M a A r e B$ and CP strains on 1/4SDAY medium without or with $150 \mu \mathrm{g} / \mathrm{mL}$ CFW. (B) Relative growth inhibition rates. (C) Microscopic observation of hyphal growth for each strain on 1/4SDAY medium without or with CFW. (D) Determination of cell wall compositions for each strain. (E) Transcription levels of genes involved in the cell wall integrity. A\&B, $p<0.05$ (Tukey's HSD). The $p$-values in Figure 5B,D,E are listed in supplementary Table S3.

\subsection{Disruption of MaAreB Decreased Virulence}

Bioassays were performed to test the virulence of the fungal strains through topical inoculation and intra-hemocoel injection. The topical inoculation experiment showed that the survival rates of locusts infected by the $\triangle M a A r e B$ strain were higher than those of the WT or CP strain at the same infection time, and visualization of locust cadavers killed by the $\triangle M a A r e B$ strain indicated less conidiation at $8 \mathrm{dpi}$ (Figure $6 \mathrm{~A}$ ). The $\mathrm{LT}_{50}$ of the $\triangle M a A r e B$ strain was $6.72 \pm 0.11 \mathrm{~d}$, which was significantly higher than that of the WT $(6.08 \pm 0.09 \mathrm{~d})$ or $\mathrm{CP}(6.18 \pm 0.08 \mathrm{~d})$ strain (Figure $6 \mathrm{~B})$. Furthermore, the quantification of the DNA concentrations of hyphal bodies in the locust hemolymph was performed by quantitative PCR. As a result, the fungal DNA concentrations in locusts infected by the $\triangle M a A r e B$ strain were markedly decreased at 4 dpi and 6 dpi compared to those infected by the WT or CP strain via topical inoculation (Figure $6 \mathrm{C}$ ). Similarly, the number of hyphal bodies were also reduced greatly in those infected by the $\Delta M a$ AreB strain (Figure $6 \mathrm{D}, \mathrm{E}$ ). 

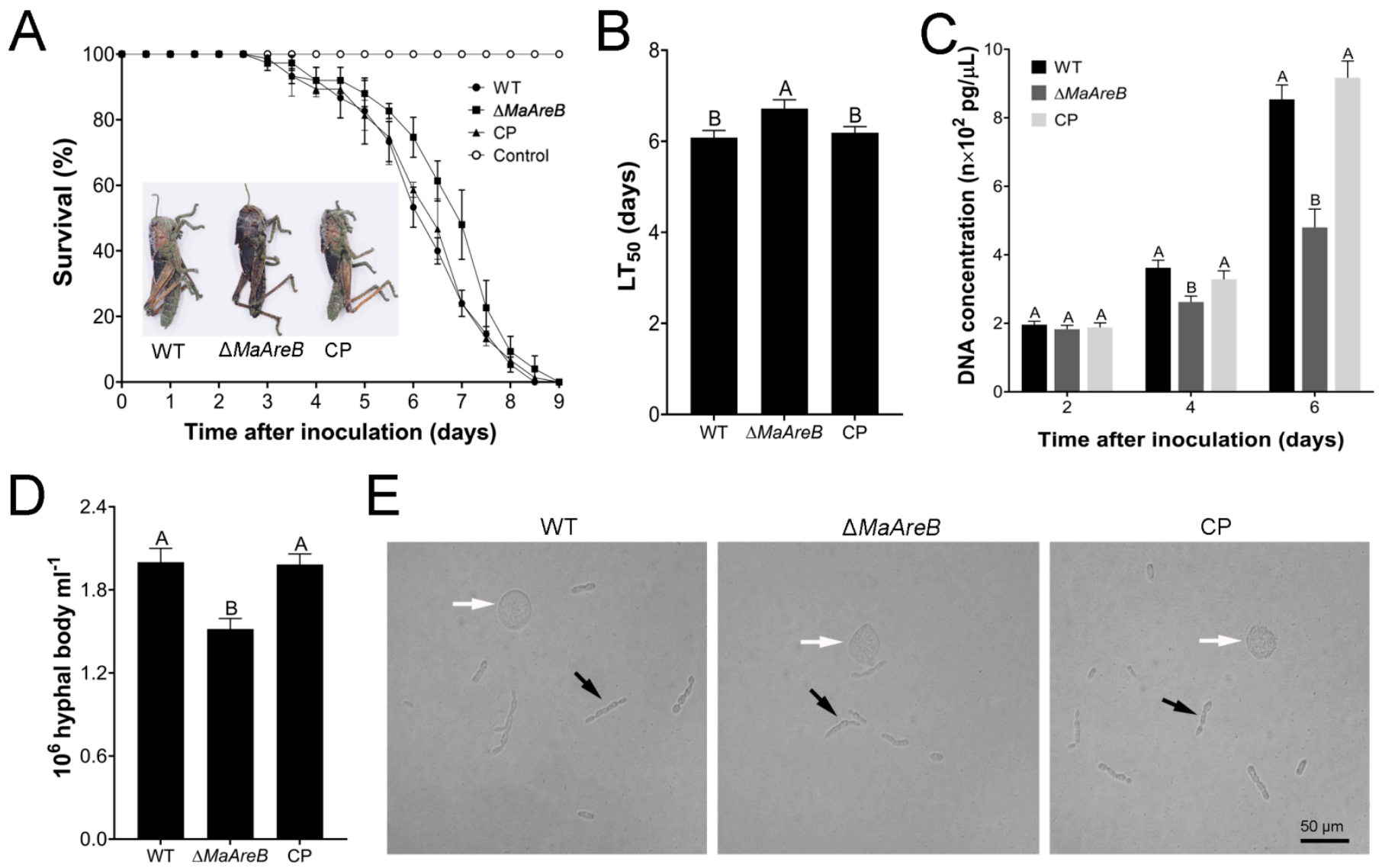

Figure 6. Loss of $M a A r e B$ reduced the virulence in topical inoculation. (A) Survival rates of locusts after infection with the WT, $\triangle M a A r e B$ and CP strains in topical inoculation test, respectively. Locust cadavers killed by each strain were cultured at $28{ }^{\circ} \mathrm{C}$ for 8 days. (B) $\mathrm{LT}_{50} \mathrm{~s}$ of fungal strains in topical inoculation test. (C) DNA concentrations of M. acridum in hemolymph of locusts infected with the WT, $\triangle M a A r e B$ and CP strains for 2, 4 and 6 days in topical inoculation test. For each treatment, $600 \mu \mathrm{L}$ blood was taken from 20 locusts ( $30 \mu \mathrm{L}$ per locust) to extract the genomic DNA. The fungal DNA concentrations were determined using quantitative PCR with primer pair of ITS-F/ITS-R (Table S1) as described previously [39]. (D) The number of hyphal bodies in locust hemolymph by topical inoculation at 6 dpi. dpi, days post inoculation. (E) Microscopic images of hyphal bodies in locust hemolymph by topical inoculation at $6 \mathrm{dpi}$. The white arrows indicate the locust blood cells, and the black arrows indicate the hyphal bodies. A\&B, $p<0.05$ (Tukey's HSD). The $p$-values in Figure 6B-D are listed in supplementary Table S3.

For the injection experiment, however, there was no significantly difference in the survival rates of locusts (Figure $\mathrm{S} 2 \mathrm{~A}$ ), the $\mathrm{LT}_{50} \mathrm{~s}$ (Figure S2B), the fungal DNA concentrations (Figure S2C) and the number of hyphal bodies in locusts among all fungal strains (Figure S2D,E). Taken together, these results indicated that loss of MaAreB severely affected the insect cuticle penetration process, reducing the virulence of $M$. acridum.

Furthermore, the conidial germinations and appressorium formations of fungal strains were determined on the locust hind wings. The conidial germination was accelerated with the deletion of MaAreB (Figure 7A). The $\mathrm{GT}_{50}$ of the $\triangle M a A r e B$ strain $(5.07 \pm 0.09 \mathrm{~h}$ ) was significantly lower than that of the WT $(6.62 \pm 0.18 \mathrm{~h})$ or CP $(6.76 \pm 0.15 \mathrm{~h})$ strain (Figure 7B). However, the appressorium formation of the $\triangle M a A r e B$ strain $(52.00 \%)$ was heavily decreased compared to that of the WT $(72.67 \%)$ or CP $(72.33 \%)$ strain after $24 \mathrm{~h}$ (Figure 7C). qRT-PCR analyses showed that genes involved in fungal adhesion (MaMad1 and MaMad2) and cuticle penetration (MaPr1 and MaChit1) were significantly downregulated in the $\triangle M a A r e B$ strain (Figure $7 D$ ). The data indicated that loss of MaAreB affected the conidial germination and appressorium formation on the locust hind wings and the expression of genes related to adhesion and cuticle penetration. 

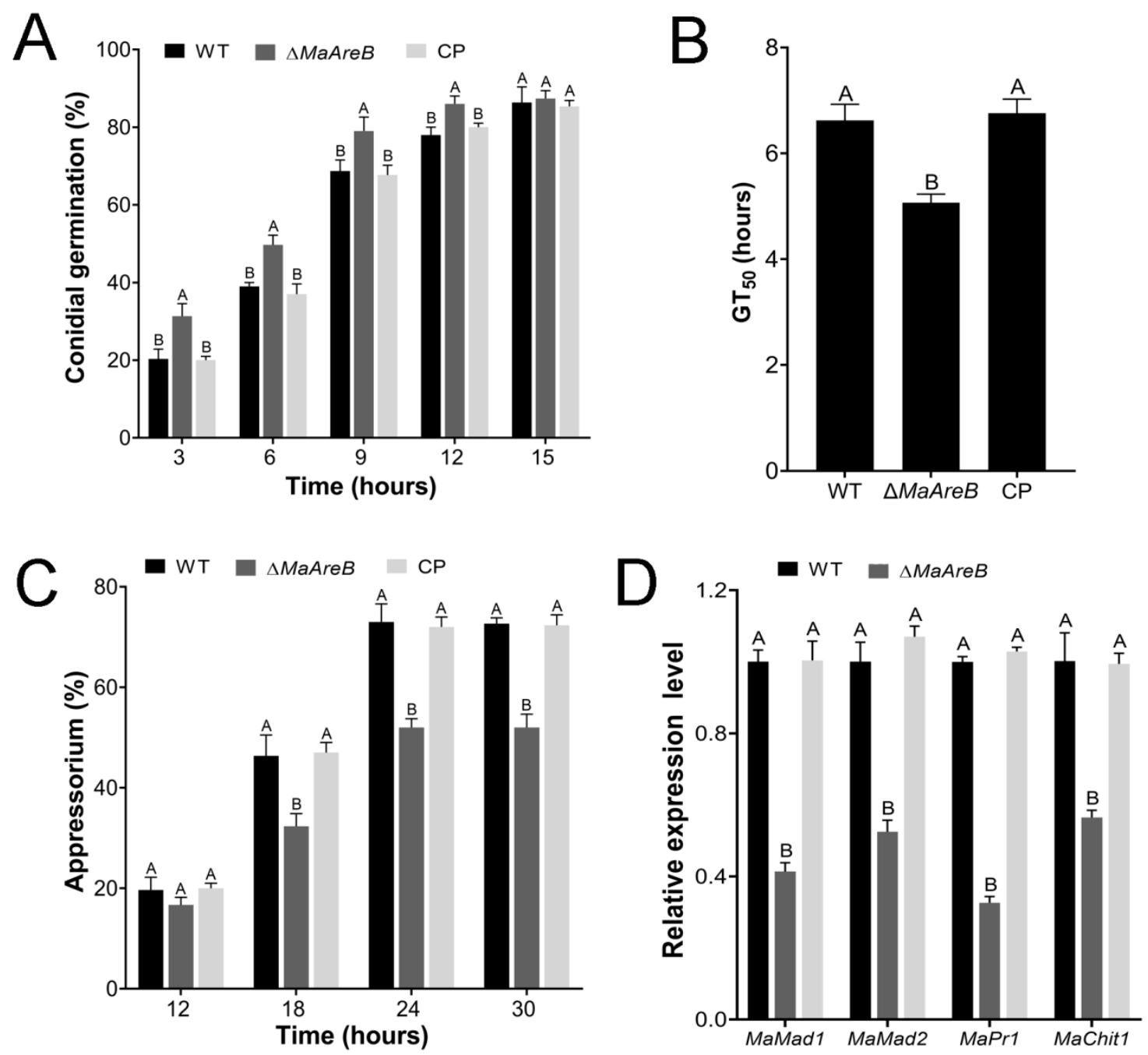

Figure 7. Lack of $M a A r e B$ impaired appressorium formation. The conidial germinations (A), $\mathrm{GT}_{50} \mathrm{~S}(\mathbf{B})$ and appressorium formations (C) of the WT, $\triangle M a A r e B$ and $\mathrm{CP}$ strains on the locust hind wings cultured at $28{ }^{\circ} \mathrm{C}$ for hours. (D) qRT-PCR analysis of genes involved in adhesion (MaMad1 and MaMad2) and cuticle penetration (MaPr1 and MaChit1). A\&B, $p<0.05$ (Tukey's HSD). The $p$-values in Figure 7A-D are listed in supplementary Table S3.

Turgor pressure is closely involved in the penetration of appressorium [9]. The appressorium collapsed rates of fungal strains were examined in different concentrations of PEG8000. The results showed that the appressorium collapsed rates of the $\triangle M a A r e B$ strain were increased significantly compared with that from the WT or CP strain (Figure 8A). The glycerol produced by lipids in appressorium can enhance turgor pressure and promote the penetration of appressorium $[41,43,44]$. qRT-PCR analyses showed that the transcription of glycerol synthesis-related genes, MaGPD1 and MaMPL1 decreased significantly in $\triangle M a A r e B$ (Figure $8 \mathrm{~B}$ ). Nile red staining demonstrated that the fluorescence intensity of the neutral lipids in appressoria of the $\triangle M a A r e B$ strain was weaker than that in the WT or CP strain (Figure 8C,D). 

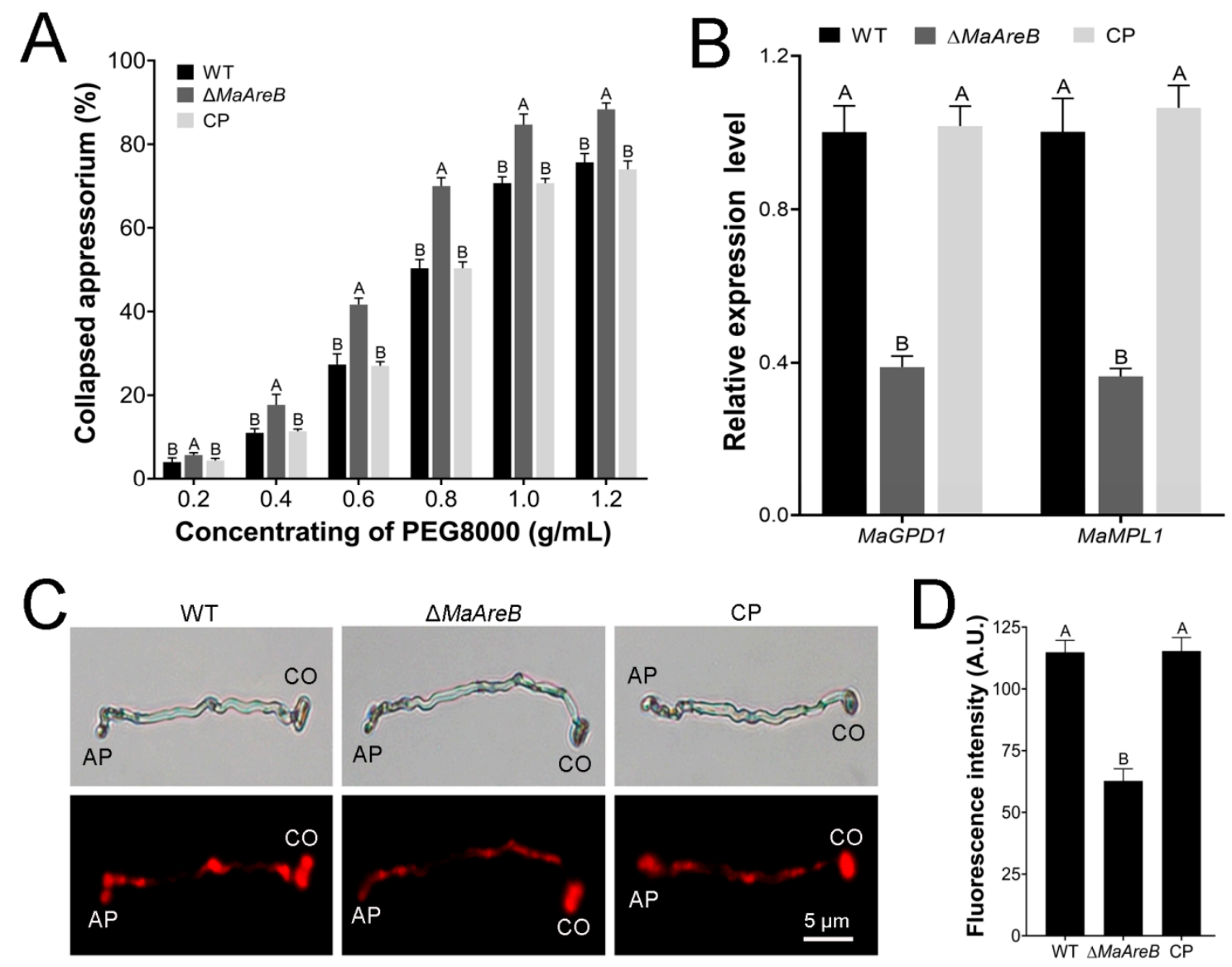

Figure 8. Lack of $M a A r e B$ decreased appressorial turgor pressure. (A) The appressorium collapsed rates of the WT, $\triangle M a A r e B$ and CP strains after treatment with different concentrations of PEG8000. (B) qRT-PCR analysis of genes related to glycerol synthesis. (C) The neutral lipids stained using Nile red in appressoria. CO, conidium. AP, appressorium. Fungal samples were cultured on locust hind wings at $28^{\circ} \mathrm{C}$ for $27 \mathrm{~h}$. (D) Fluorescence intensity of the neutral lipids in appressoria. A.U., Arbitrary Units. A\&B, $p<0.05$ (Tukey's HSD). The $p$-values in Figure 8A,B,D are listed in supplementary Table S3.

\section{Discussion}

GATA transcription factors play vital roles in the NCR pathway, and regulate cell differentiation in different tissues [45]. The classical GATA transcription factor functions as a transcription activator and contains a transcription activation region at the $\mathrm{N}$-terminal [45]. In filamentous fungi, only two GATA transcription factors, AreA and AreB, are found in the NCR pathway, among which AreA plays a positive regulatory role and AreB plays a repressive role $[13,46]$. AreA is a global transcriptional regulator related to nitrogen metabolism in filamentous fungi, which can activate the transcription of genes related to the secondary nitrogen metabolism, and it has been reported in many fungi, such as A. nidulans [47-49], A. parasiticus [50], Gibberella fujikuroi [51], F. verticillioides [26], and F. fujikuroi [18]. On the contrary, there are a few studies on AreB in filamentous fungi, which mainly focus on nitrogen metabolism and the regulatory relationship with NCR related genes $[11,14,24]$. In this study, we identified the AreB homologous protein, MaAreB, in the model insect pathogenic fungus M. acridum. The functions of MaAreB in nitrogen utilization, growth and development, tolerance to both, and virulence were characterized.

Based on the functions of GATA transcription factors in nitrogen metabolism, we explored the selective utilization of nitrogen sources by MaAreB. The results showed that the utilization ability of both preferential utilization glutamine and less easily assimilated nitrate were decreased in the $\triangle M a A r e B$ strain. Although there was no significant difference in colony diameter on the ammonium, the conidial yield was significantly reduced in $\triangle M a A r e B$. These results suggested that $M a A r e B$ was also involved in regulating nitrogen 
utilization in M. acridum. Furthermore, loss of MaAreB resulted in a delay in conidial germination and a decrease in conidial yield when fungal strains were grown on the complete medium (1/4SDAY), indicating that MaAreB was involved in regulating the development and asexual sporulation.

Metarhizium spp. is a kind of important biocontrol fungus, which can infect a variety of agricultural pests [52-56]. The adaptability of entomopathogenic fungi to the adverse environment directly determine the efficacy of mycoinsecticides [57]. In this study, we found that loss of $M a A r e B$ reduced the tolerances to UV-B irradiation and heat-shock in M. acridum. As a powerful physiological barrier, the fungal cell wall involves a variety of physiological functions, such as nutrient uptake and cell attachment, maintaining the inherent morphology of fungal cells, and protecting cells from external adversity conditions [58-61]. Our results showed that $M a A r e B$ affected the cell wall integrity of $M$. acridum. The hyphal growth and colony morphology of the $\triangle M a A r e B$ strain were seriously inhibited by CFW, which could bind to the nascent chitin chain to prevent the formation of co-crystals and microfibrils [62]. Chitin is synthesized by chitin synthases and is crucial to the fungal cell wall integrity [63]. Studies have shown that ChsIII, ChsV, ChsVI and ChsVII affect the synthesis of polysaccharide in the cell wall, and ChsIII, ChsV and ChsVII are necessary for the cell wall integrity in M. acridum [36]. In addition, chitin syn synthases in A. fumigatus [64] and Botrytis cinerea [65] also affect the cell wall integrity. We found that the contents of chitin and $\beta-1,3$-glucan, the essential components of the fungal cell wall, in $\triangle M a A r e B$ strain were heavily decreased. Consistently, some genes encoding chitin synthases or $\beta$-1,3-glucan synthase were significantly down-regulated. Therefore, we speculated that $M a A r e B$ might make contributions to the fungal sensitivity and resistance to the external environment by affecting the cell wall integrity.

Studies in many fungi, such as Ustilago maydis [66], M. oryzae [67], and A. fumigatus [64,68], have pointed out that the change of chitin content in the cell wall affects appressorium formation, which in turn affects the host immune defense. In this study, we found that disruption of $M a A r e B$ affected the synthesis of fungal cell wall components and cell wall integrity. The virulence test showed that the virulence of the $\triangle M a A r e B$ strain was significantly decreased in topical inoculation, while it was not significantly different from that of the WT or CP strain in intra-hemocoel injection, indicating that MaAreB was conducive for $M$. acridum to penetrate the host cuticle. The ability of conidium to penetrate the host cuticle was directly determined by its adhesion, germination, and appressorium formation on the host cuticle [8]. Our study proved that the appressorium formation, the appressorium turgor pressure, and the transcription of genes related to adhesion (MaMad1 and MaMad2) and penetration (MaPr1 and MaChit1) were all significantly reduced in the $\triangle M a A r e B$ strain. Appressoria of entomopathogenic fungi are necessary for infecting host, and the turgor pressure and cuticle degrading enzymes can promote appressoria to penetrate the host cuticle [9]. These data further confirmed that MaAreB played an important role in insect cuticle penetration of $M$. acridum.

Nitrogen metabolism is not only involved in regulating the nutrient utilization of fungi, but also closely involved in the virulence of pathogenic fungi. Glutamine, a preferential nitrogen source, could inhibit the virulence of $M$. oryzae $[28,69]$ and F. oxysporum [70]. Deletion of $M o G \ln 1$, the glutamine synthetase gene, would affect the virulence of infecting hyphae in M. oryzae [69]. During the process of host infection by entomopathogenic fungi, conidial germination [71,72] and appressorium formation [73] are closely related to nitrogen source conditions. $B$. bassiana needs to activate its own intracellular nitrogen metabolism level to promote conidial germination; if not, the conidia cannot form germ tubes [74]. Nitrogen starvation can promote appressorium formation in M. anisopliae [75]. Nitrogen starvation can induce the expression of many pathogenesis related genes; hence it is also regarded as the driving force for pathogenic fungi to infect the host [76,77]. In M. oryzae, deletion of $A s d 4$, the $A r e B$ homologous gene, could increase glutamine content and activate TOR (Target of Rapamycin) pathway, and result in the inability to form appressorium [28]. However, the appressorium formation could be restored with knocking 
out $G \ln 1$ or inhibiting TOR path under $\Delta A s d 4$ background [28]. In M. acridum, MaAreB was involved in regulating nitrogen metabolism and virulence, but it was still unclear whether there was a certain correlation between nutrient utilization and virulence. Whether $M a A r e B$ affects virulence by inducing nitrogen metabolism remains to be explored in the near future.

\section{Conclusions}

Nutrients are very important for fungal growth and development. It is well known that the NCR pathway plays crucial roles in the regulation of fungal nitrogen metabolism. During these processes, GATA-type transcription factors, such as AreA and AreB, play indispensable roles. Although AreA has been reported in many fungi, the second GATA transcription factor AreB is less studied than AreA. The functions of AreB are largely unknown in entomopathogenic fungi. In this study, we focused on functional characterization of the second GATA transcription factor MaAreB in the model entomopathogenic fungus M. acridum. Deletion of $M a A r e B$ affected the fungal cell wall integrity and reduced fungal virulence due to weakening the cuticle penetration of $M$. acridum. However, the roles of $M a A r e B$ in nitrogen utilization needs to be further investigated in M. acridum. In general, these results provide insights into understanding the functions of AreB homologous proteins in other filamentous fungi.

Supplementary Materials: The following are available online at https: / www.mdpi.com/article / 10.3390/jof7070512/s1, Figure S1: Vector construction and Southern blotting. Schematic diagram of MaAreB knockout (A) and complemented (B) vector constructions. (C) Verification of the WT, $\triangle M a A r e B$ and $C P$ strains by Southern blotting. Probe was amplified with primers AreB-PF/AreB-PR (Table S1). Restriction enzyme EcoRV and SacII were used to digest the genome DNA of the WT, $\triangle M a A r e B$ and $C P$ strains. Figure S2: Loss of $M a A r e B$ did not affected the virulence in intra-hemocoel injection. (A) Survival rates of locusts infected with the WT, $\triangle M a A r e B$ and CP strains in intrahemocoel injection, respectively. Locust cadavers killed by fungal strains were cultured at $28^{\circ} \mathrm{C}$ for 8 days. (B) $\mathrm{LT}_{50} \mathrm{~s}$ of fungal strains in intra-hemocoel injection test. (C) DNA concentrations of M. acridum in hemolymph of locust infected with the WT, $\triangle M a A r e B$ and CP strains for $1 \mathrm{~d}, 3 \mathrm{~d}$ and $5 \mathrm{~d}$ in intra-hemocoel injection test. For each treatment, $600 \mu \mathrm{L}$ blood was taken from 20 locusts (30 $\mu \mathrm{L}$ for a locust) to extract the genomic DNA. The fungal DNA concentrations were determined using quantitative PCR with primer pair of ITS-F/ITS-R (Table S1) as described previously [39]. (D) The number of hyphal bodies in locust hemolymph by intra-hemocoel injection at 5 dpi. (E) Microscopic images of hyphal bodies in locust hemolymph by intra-hemocoel injection at $5 \mathrm{dpi}$. dpi, days post inoculation. The white arrows indicate the locust blood cells, and the black arrows indicate the hyphal bodies. A\&A, $p>0.05$ (Tukey's HSD). The $p$ values in Figure S2B-D were listed in supplementary Table S3. Table S1: Primers used in this study. Table S2: Parameter information of primer pairs used in qRT-PCR. Table S3: The $p$-values in each experiment.

Author Contributions: Conceptualization, Y.X. and K.J.; Data curation, C.L. and Q.Z.; Funding acquisition, Y.X. and K.J.; Investigation, C.L. and Q.Z.; Methodology, Y.X. and K.J.; Project administration, Y.X. and K.J.; Software, C.L.; Writing-Original draft, C.L.; Writing-Review \& editing, K.J. All authors have read and agreed to the published version of the manuscript.

Funding: This work was supported by the National Key R \& D Program of China (2019YFD1002100), the Venture \& Innovation Support Program for Chongqing Overseas Returnees (cx2019035), the Natural Science Foundation Project of Chongqing (cstc2018jcyjAX0554).

Institutional Review Board Statement: Not applicable.

Informed Consent Statement: Not applicable.

Data Availability Statement: Not applicable.

Conflicts of Interest: The authors declare no conflict of interest. 


\section{References}

1. San-Blas, G.; Travassos, L.R.; Fries, B.C.; Goldman, D.L.; Casadevall, A.; Carmona, A.K.; Barros, T.F.; Puccia, R.; Hostetter, M.K.; Shanks, S.G.; et al. Fungal morphogenesis and virulence. Med. Mycol. 2000, 38, 79-86. [CrossRef]

2. Tournas, V.H. Spoilage of vegetable crops by bacteria and fungi and related health hazards. Crit. Rev. Microbiol. 2005, 31, 33-44. [CrossRef] [PubMed]

3. Kurtti, T.J.; Keyhani, N.O. Intracellular infection of tick cell lines by the entomopathogenic fungus Metarhizium anisopliae. Microbiol. 2008, 154, 1700-1709. [CrossRef] [PubMed]

4. Wanchoo, A.; Lewis, M.W.; Keyhani, N.O. Lectin mapping reveals stage-specific display of surface carbohydrates in in vitro and haemolymph-derived cells of the entomopathogenic fungus Beauveria bassiana. Microbiology 2009, 155, 3121-3133. [CrossRef] [PubMed]

5. Shoresh, M.; Harman, G.E.; Mastouri, F. Induced systemic resistance and plant responses to fungal biocontrol agents. Annu. Rev. Phytopathol. 2010, 48, 21-43. [CrossRef] [PubMed]

6. Moore, D.; Lord, J.C.; Smith, S.M. Pathogens. In Alternatives to Pesticides in Stored Product IPM; Subramanyam, B., Hagstrum, D.W., Eds.; Kluwer Academic Publishers: Boston, MA, USA, 2000; pp. 193-227. [CrossRef]

7. Athanassiou, C.G.; Kavallieratos, N.G.; Vayias, B.J.; Tsakiri, J.B.; Mikeli, N.H.; Meletsis, C.M.; Tomanović, Ž. Persistence and efficacy of Metarhizium anisopliae (Metschnikoff) Sorokin (Deuteromycotina: Hyphomycetes) and diatomaceous earth against Sitophilus oryzae (L.) (Coleoptera: Curculionidae) and Rhyzopertha dominica (F.) (Coleoptera: Bostrychidae) on wheat and maize. Crop. Protect. 2008, 27, 1303-1311. [CrossRef]

8. Clarkson, J.M.; Charnley, A.K. New insights into the mechanisms of fungal pathogenesis in insect. Trends Microbiol. 1996, 4, 197-203. [CrossRef]

9. St Leger, R.; Joshi, L.; Bidochka, M.J.; Roberts, D.W. Construction of an improved mycoinsecticide overexpressing a toxic protease. Proc. Natl. Acad. Sci. USA 1996, 93, 6349-6354. [CrossRef]

10. Fang, W.; Leng, B.; Xiao, Y.; Jin, K.; Ma, J.; Fan, Y.; Feng, J.; Yang, X.; Zhang, Y.; Pei, Y. Cloning of Beauveria bassiana chitinase gene Bbchit1 and its application to improve fungal strain virulence. Appl. Environ. Microbiol. 2005, 71, 363-370. [CrossRef]

11. Tudzynski, B. Nitrogen regulation of fungal secondary metabolism in fungi. Front. Microbiol. 2014, 5, 656. [CrossRef]

12. Marzluf, G.A. Genetic regulation of nitrogen metabolism in the fungi. Microbiol. Mol. Biol. Rev. 1997, 61, 17-32. [CrossRef]

13. Wong, K.H.; Hynes, M.J.; Davis, M.A. Recent advances in nitrogen regulation: A comparison between Saccharomyces cerevisiae and filamentous fungi. Eukaryot. Cell 2008, 7, 917-925. [CrossRef]

14. Wong, K.H.; Hynes, M.J.; Todd, R.B.; Davis, M.A. Deletion and overexpression of the Aspergillus nidulans GATA factor AreB reveals unexpected pleiotropy. Microbiology 2009, 155, 3868-3880. [CrossRef] [PubMed]

15. Langdon, T.; Sheerins, A.; Ravagnani, A.; Gielkens, M.; Caddick, M.X.; Arst, H.N., Jr. Mutational analysis reveals dispensability of the N-terminal region of the Aspergillus transcription factor mediating nitrogen metabolite repression. Mol. Microbiol. 1995, 17, 877-888. [CrossRef]

16. Fu, Y.H.; Marzluf, G.A. Characterization of nit-2, the major nitrogen regulatory gene of Neurospora crassa. Mol. Cell. Biol. 1987, 7, 1691-1696. [CrossRef] [PubMed]

17. Froeliger, E.H.; Carpenter, B.E. NUT1, a major nitrogen regulatory gene in Magnaporthe grisea, is dispensable for pathogenicity. Mol. Gen. Genet. 1996, 251, 647-656. [CrossRef]

18. Michielse, C.B.; Pfannmüller, A.; Macios, M.; Rengers, P.; Dzikowska, A.; Tudzynski, B. The interplay between the GATA transcription factors AreA, the global nitrogen regulator and AreB in Fusarium fujikuroi. Mol. Microbiol. 2014, 91, 472-493. [CrossRef]

19. Bi, F.; Ment, D.; Luria, N.; Meng, X.; Prusky, D. Mutation of AREA affects growth, sporulation, nitrogen regulation, and pathogenicity in Colletotrichum gloeosporioides. Fungal Genet. Biol. 2017, 99, 29-39. [CrossRef] [PubMed]

20. Pomraning, K.R.; Bredeweg, E.L.; Baker, S.E. Regulation of nitrogen metabolism by GATA zinc finger transcription factors in Yarrowia lipolytica. mSphere 2017, 2, e00038-17. [CrossRef]

21. Fasoyin, O.E.; Yang, K.; Qiu, M.; Wang, B.; Wang, S.; Wang, S. Regulation of morphology, aflatoxin production, and virulence of Aspergillus flavus by the major nitrogen regulatory gene areA. Toxins 2019, 11, 718. [CrossRef]

22. Li, J.; Pan, Y.; Liu, G. Disruption of the nitrogen regulatory gene AcareA in Acremonium chrysogenum leads to reduction of cephalosporin production and repression of nitrogen metabolism. Fungal Genet. Biol. 2013, 61, 69-79. [CrossRef]

23. Conlon, H.; Zadra, I.; Haas, H.; Arst, H.N.; Jones, M.G., Jr.; Caddick, M.X. The Aspergillus nidulans GATA transcription factor gene areB encodes at least three proteins and features three classes of mutation. Mol. Microbiol. 2001, 40, 361-375. [CrossRef]

24. Haas, H.; Angermayr, K.; Zadra, I.; Stoffler, G. Overexpression of nreB, a new GATA factor-encoding gene of Penicillium chrysogenum, leads to repression of the nitrate assimilatory gene cluster. J. Biol. Chem. 1997, 272, 22576-22582. [CrossRef]

25. Teichert, S.; Rutherford, J.C.; Wottawa, M.; Heitman, J.; Tudzynski, B. Impact of the ammonium permeases MepA, MepB, and MepC on nitrogen-regulated secondary metabolism in Fusarium fujikuroi. Eukaryot. Cell 2008, 7, 187-201. [CrossRef]

26. Schönig, B.; Brown, D.W.; Oeser, B.; Tudzynski, B. Cross-species hybridization with Fusarium verticillioides microarrays reveals new insights into Fusarium fujikuroi nitrogen regulation and the role of AreA and NMR. Eukaryot. Cell 2008, 7, 1831-1846. [CrossRef]

27. Feng, B.; Haas, H.; Marzluf, G.A. ASD4, a new GATA factor of Neurospora crassa, displays sequence-specific DNA binding and functions in ascus and ascospore development. Biochemistry 2000, 39, 11065-11073. [CrossRef] [PubMed] 
28. Marroquin-Guzman, M.; Wilson, R.A. GATA-dependent glutaminolysis drives appressorium formation in Magnaporthe oryzae by suppressing TOR inhibition of cAMP/PKA signaling. PLoS Pathog. 2015, 11, e1004851. [CrossRef]

29. Tamura, K.; Stecher, G.; Peterson, D.; Filipski, A.; Kumar, S. MEGA6: Molecular evolutionary genetics analysis version 6.0. Mol. Biol. Evol. 2013, 30, 2725-2729. [CrossRef]

30. Du, Y.; Jin, K.; Xia, Y. Involvement of MaSom1, a downstream transcriptional factor of cAMP/PKA pathway, in conidial yield, stress tolerances, and virulence in Metarhizium acridum. Appl. Microbiol. Biot. 2018, 102, 5611-5623. [CrossRef] [PubMed]

31. Jin, K.; Ming, Y.; Xia, Y.X. MaHog1, a Hog1-type mitogen-activated protein kinase gene, contributes to stress tolerance and virulence of the entomopathogenic fungus Metarhizium acridum. Microbiology 2012, 158, 2987-2996. [CrossRef] [PubMed]

32. dos Reis, M.C.; Pelegrinelli Fungaro, M.H.; Delgado Duarte, R.T.; Furlaneto, L.; Furlaneto, M.C. Agrobacterium tumefaciensmediated genetic transformation of the entomopathogenic fungus Beauveria bassiana. J. Microbiol. Methods 2004, 58, 197-202. [CrossRef] [PubMed]

33. Liu, J.; Cao, Y.Q.; Xia, Y.X. Mmc, a gene involved in microcycle conidiation of the entomopathogenic fungus Metarhizium anisopliae. J. Invertebr. Pathol. 2010, 105, 132-138. [CrossRef]

34. Zhang, S.Z.; Peng, G.X.; Xia, Y.X. Microcycle conidiation and the conidial properties in the entomopathogenic fungus Metarhizium acridum on agar medium. Biocontrol Sci. Technol. 2010, 20, 809-819. [CrossRef]

35. Su, X.; Yan, X.; Chen, X.; Guo, M.; Xia, Y.; Cao, Y. Calcofluor white hypersensitive proteins contribute to stress tolerance and pathogenicity in entomopathogenic fungus, Metarhizium acridum. Pest Manag. Sci. 2021, 77, 1915-1924. [CrossRef]

36. Zhang, J.; Jiang, H.; Du, Y.; Keyhani, N.O.; Xia, Y.; Jin, K. Members of chitin synthase family in Metarhizium acridum differentially affect fungal growth, stress tolerances, cell wall integrity and virulence. PLoS Pathog. 2019, 15, e1007964. [CrossRef] [PubMed]

37. Livak, K.J.; Schmittgen, T.D. Analysis of relative gene expression data using real-time quantitative PCR and the $2^{-\Delta \Delta C t}$ method. Methods 2001, 25, 402-408. [CrossRef]

38. Peng, G.X.; Xia, Y.X. The mechanism of themycoinsecticide diluent on the efficacy of the oil formulation of insecticidal fungus. BioControl 2011, 56, 893-902. [CrossRef]

39. Guo, H.Y.; Wang, H.J.; Keyhani, N.O.; Xia, Y.X.; Peng, G.X. Disruption of an adenylate-forming reductase required for conidiation, increases virulence of the insect pathogenic fungus Metarhizium acridum by enhancing cuticle invasion. Pest Manag. Sci. 2020, 76, 758-768. [CrossRef]

40. Ming, Y.; Wei, Q.L.; Jin, K.; Xia, Y.X. MaSnf1, a sucrose non-fermenting protein kinase gene, is involved in carbon source utilization, stress tolerance, and virulence in Metarhizium acridum. Appl. Microbiol. Biot. 2014, 98, 10153-10164. [CrossRef]

41. Wang, C.S.; St Leger, R.J. The Metarhizium anisopliae perilipin homolog MPL1 regulates lipid metabolism, appressorial turgor pressure, and virulence. J. Biol. Chem. 2007, 282, 21110-21115. [CrossRef] [PubMed]

42. Gow, N.A.R.; Latgé, J.P.; Munro, C.A. The fungal cell wall: Structure, biosynthesis, and function. Microbiol. Spectr. 2017, 5. [CrossRef]

43. Kopp, M.; Müller, H.; Holzer, H. Molecular analysis of the neutral trehalase gene from Saccharomyces cerevisiae. J. Biol. Chem. 1993, 268, 4766-4774. [CrossRef]

44. Keyhani, N.O. Lipid biology in fungal stress and virulence: Entomopathogenic fungi. Fungal Biol. 2017, 112, 420-429. [CrossRef]

45. Limjindaporn, T.; Khalaf, R.A.; Fonzi, W.A. Nitrogen metabolism and virulence of Candida albicans require the GATA-type transcriptional activator encoded by GAT1. Mol. Microbiol. 2003, 50, 993-1004. [CrossRef]

46. Wiemann, P.; Tudzynski, B. The nitrogen regulation network and its impact on secondary metabolism and pathogenicity. In Fusarium: Genomics, Molecular and Cellular Biology; Brown, D.W., Proctor, R.H., Eds.; Caister Academic Press: Norwich, UK, 2013; pp. 111-146.

47. Platt, A.; Ravagnani, A.; Arst, H., Jr.; Kirk, D.; Langdon, T.; Caddick, M.X. Mutational analysis of the C-terminal region of AREA, the transcription factor mediating nitrogen metabolite repression in Aspergillus nidulans. Mol. Gen. Genet. 1996, 250, 106-114. [CrossRef]

48. Caddick, M.X.; Arst, H.N. Deletion of the 389 N-terminal residues of the transcriptional activator AREA does not result in nitrogen metabolite derepression in Aspergillus nidulans. J. Bacteriol. 1998, 180, 5762-5764. [CrossRef]

49. Macios, M.; Caddick, M.X.; Weglenski, P.; Scazzocchio, C.; Dzikowska, A. The GATA factors AREA and AREB together with the co-repressor NMRA, negatively regulate arginine catabolism in Aspergillus nidulans in response to nitrogen and carbon source. Fungal Genet. Biol. 2012, 49, 189-198. [CrossRef] [PubMed]

50. Chang, P.K.; Yu, J.; Bhatnagar, D.; Cleveland, T.E. Characterization of the Aspergillus parasiticus major nitrogen regulatory gene, areA. Biochim. Biophys. Acta 2000, 1491, 263-266. [CrossRef]

51. Mihlan, M.; Homann, V.; Liu, T.W.; Tudzynski, B. AREA directly mediates nitrogen regulation of gibberellin biosynthesis in Gibberella fujikuroi, but its activity is not affected by NMR. Mol. Microbiol. 2003, 47, 975-991. [CrossRef]

52. Lomer, C.J.; Bateman, R.P.; Johnson, D.L.; Langewald, J.; Thomas, M.B. Biological control of locusts and grasshoppers. Annu. Rev. Entomol. 2001, 46, 667-702. [CrossRef] [PubMed]

53. Maniania, N.K.; Sithanantham, S.; Ekesi, S.; Ampong-Nyarko, K.; Baumgärtner, J.; Löhr, B.; Matoka, C.M. A field trial of the entomogenous fungus Metarhizium anisopliae for control of onion thrips, Thrips tabaci. Crop. Prot. 2003, 22, 553-559. [CrossRef]

54. Roberts, D.W.; St Leger, R.J. Metarhizium spp., cosmopolitan insect-pathogenic fungi: Mycological aspects. Adv. Appl. Microbiol. 2004, 54, 1-70. [CrossRef] 
55. Peng, G.X.; Wang, Z.K.; Yin, Y.P.; Zeng, D.Y.; Xia, Y.X. Field trials of Metarhizium anisopliae var. acridum (Ascomycota: Hypocreales) against oriental migratory locusts, Locusta migratoria manilensis (Meyen) in Northern China. Crop. Prot. 2008, 27, 1244-1250. [CrossRef]

56. Nong, X.; Liu, C.; Lu, X.; Wang, Q.; Wang, G.; Zhang, Z. Laboratory evaluation of entomopathogenic fungi against the white grubs, Holotrichia oblita and Anomala corpulenta (Coleoptera: Scarabaeidae) from the field of peanut, Arachis hypogaea. Biocontrol Sci. Technol. 2011, 21, 593-603. [CrossRef]

57. Ortizurquiza, A.; Luo, Z.; Keyhani, N.O. Improving mycoinsecticides for insect biological control. Appl. Microbiol. Biot. 2015, 99, 1057-1068. [CrossRef] [PubMed]

58. Huxham, I.M.; Samuels, K.D.Z.; Heale, J.B. In vivo and in vitro assays for pathogenicity of wildtype and mutant strainof Metarhizium anisopliaefor three insect species. J. Invertebr. Pathol. 1989, 53, 143-151. [CrossRef]

59. Kershaw, M.J.; Moorhouse, E.R.; Bateman, R.; Reynolds, S.E.; Charnley, A.K. The role of destruxins in the pathogenicity of Metarhizium anisopliae for three species of insect. J. Invertebr. Pathol. 1999, 74, 213-223. [CrossRef]

60. Angiolella, L.; Micocci, M.M.; Dalessio, S.; Girolamo, A.; Maras, B.; Cassone, A. Identification of major glucan-associated cell wall proteins of Candida albicans and their role in fluconazole resistance. Antimicrob. Agents Chemother. 2002, 46, 688-694. [CrossRef]

61. Lesage, G.; Bussey, H. Cell wall assembly in Saccharomyces cerevisiae. Microbiol. Mol. Biol. Rev. 2006, 70, 317-343. [CrossRef]

62. Elorza, M.V.; Rico, H.; Sentandreu, P. Calcofluor white alters the assembly of chitin fibrils in Saccharomyces cerevisiae and Candida albicans cells. J. Gen. Microbiol. 1983, 129, 1577-1582. [CrossRef]

63. Lenardon, M.D.; Munro, C.A.; Gow, N.A. Chitin synthesis and fungal pathogenesis. Curr. Opin. Microbiol. 2010, 13, 416-423. [CrossRef]

64. Muszkieta, L.; Aimanianda, V.; Mellado, E.; Gribaldo, S.; Alcazar-Fuoli, L.; Szewczyk, E.; Prevost, M.; Latgé, J. Deciphering the role of the chitin synthase families 1 and 2 in the in vivo and in vitro growth of Aspergillus fumigatus by multiple gene targeting deletion. Cell. Microbiol. 2014, 16, 1784-1805. [CrossRef] [PubMed]

65. Soulie, M.C.; Piffeteau, A.; Choquer, M.; Boccara, M.; Vidal-Cros, A. Disruption of Botrytis cinerea class I chitin synthase gene Bcchs1 results in cell wall weakening and reduced virulence. Fungal Genet. Biol. 2003, 40, 38-46. [CrossRef]

66. Weber, I.; Assmann, D.E.; Thines, E.; Steinberg, G. Polar localizing class V myosin chitin synthases are essential during early plant infection in the plant pathogenic fungus Ustilago maydis. Plant Cell 2006, 18, 225-242. [CrossRef] [PubMed]

67. Kong, L.A.; Yang, J.; Li, G.T.; Qi, L.L.; Zhang, Y.J.; Wang, C.F.; Zhao, W.S.; Xu, J.R.; Peng, Y.L.; Howlett, B.J. Different chitin synthase genes are required for various developmental and plant infection processes in the rice blast fungus Magnaporthe oryzae. PLoS Pathog. 2012, 8, e1002526. [CrossRef] [PubMed]

68. Jiménez-Ortigosa, C.; Aimanianda, V.; Muszkieta, L.; Mouyna, I.; Alsteens, D.; Pire, S.; Beau, R.; Krappmann, S.; Beauvais, A.; Dufrêne, Y.F.; et al. Chitin synthases with a myosin motor-like domain control the resistance of Aspergillus fumigatus to echinocandins. Antimicrob. Agents Chemother. 2012, 56, 6121-6131. [CrossRef]

69. Zhou, W.; Shi, W.; Xu, X.W.; Li, Z.G.; Yin, C.F.; Peng, J.B.; Pan, S.; Chen, X.L.; Zhao, W.S.; Zhang, Y.; et al. Glutamate synthase MoGlt1-mediated glutamate homeostasis is important for autophagy, virulence and conidiation in the rice blast fungus. Mol. Plant Pathol. 2018, 19, 564-578. [CrossRef]

70. López-Berges, M.S.; Rispail, N.; Pradosrosales, R.C.; Pietro, A.D. A nitrogen response pathway regulates virulence functions in Fusarium oxysporum via the protein kinase TOR and the bZIP protein MeaB. Plant Cell 2010, 22, 2459-2475. [CrossRef] [PubMed]

71. Schisler, D.A.; Jackson, M.A.; Bothast, R.J. Influence of nutrition during conidiation of Colletotrichum truncatum on conidial germination and efficacy in inciting disease in Sesbania exalata. Phytopathology 1991, 81, 458-461. [CrossRef]

72. Shah, F.A.; Wang, C.S.; Butt, T.M. Nutrition influences growth and virulence of the insect-pathogenic fungus Metarhizium anisopliae. FEMS Microbiol. Lett. 2005, 251, 259-266. [CrossRef]

73. Jarrold, S.L.; Moore, D.; Potter, U.; Charnley, A.K. The contribution of surface waxes to pre-penetration growth of an entomopathogenic fungus on host cuticle. Mycol. Res. 2007, 111, 240-249. [CrossRef]

74. Vega, F.E.; Jackson, M.A.; Mercadier, G.; Poprawski, T.J. The impact of nutrition on spore yields for various fungal entomopathogens in liquid culture. World J. Microbiol. Biotechnol. 2003, 19, 363-368. [CrossRef]

75. St Leger, R.; Butt, T.M.; Goettel, M.S.; Staples, R.C.; Roberts, D.W. Production in vitro of appressoria by the entomopathogenic fungus Metarhizium anisopliae. Experimental. Mycol. 1989, 13, 274-288. [CrossRef]

76. Ackerveken, G.F.J.M.; Dunn, R.M.; Cozijnsen, A.J.; Vossen, J.P.M.J.; Broek, H.W.J.; Wit, P.J.G.M. Nitrogen limitation induces expression of the a virulence gene avr9 in the tomato pathogen Cladosporium fulvum. Mol. Gen. Genet. 1994, 243, $277-285$. [CrossRef] [PubMed]

77. Snoeijers, S.S.; Pérez-García, A.; Joosten, M.H.A.J.; De Wit, P.J.G.M. The effect of nitrogen on disease development and gene expression in bacterial and fungal plant pathogens. Eur. J. Plant Pathol. 2000, 106, 493-506. [CrossRef] 